\title{
DESARROLLO DE LA COMPRENSIÓN LECTORA EN NIÑOS CON TDAH A TRAVÉS DE LAS TIC
}

\author{
Alba Jiménez Rodríguez \\ Universidad de Huelva \\ TFG. Curso 2021 \\ Grado en Educación Primaria
}

\section{Resumen}

La llegada de un bebé al mundo trae consigo diferentes competencias y habilidades ocultas, que a lo largo de nuestro día a día, de una manera u otra, debemos desarrollar, como, por ejemplo; las emociones, el lenguaje, la comprensión lectora, etc.

La enseñanza en la etapa escolar comprendida entre los seis y doce años de edad, es considerada la más importante debido a que se manifiestan cambios significativos como son: la cognición, la afectividad y socialización. Desde la visión de una maestra en Pedagogía Terapéutica, manifiesto que en esta etapa suelen aparecer Necesidades Educativas Especiales (Trastornos del Espectro Autista, Trastorno por Déficit de atención e hiperactividad, etc.) en algunos alumnos, los cuales demandan unas necesidades más concretas que los docentes debemos cubrir.La realización de este proyecto de intervención tiene como finalidad principal desarrollar la comprensión lectora en niños y niñas que presenten TDAH en la etapa de Educación Primaria a través de las tecnologías de la información y la comunicación, TIC en adelante. De esta manera ayudaremos a dichos escolares a mejorar su comprensión lectora consiguiendo, al mismo tiempo, una mayor integridad en el aula y potenciar el manejo de las TIC.

Palabras claves: Comprensión lectora, Trastorno por Déficit de atención e hiperactividad, TIC, Educación Primaria, atención a la diversidad

\begin{abstract}
Abstrac
The arrival of a baby into the world brings with it different competencies and hidden skills, which throughout our day to day, in one way or another, we must develop, such as; emotions, language, reading comprehension, etc.

Teaching in the school stage between six and twelve years of age is considered the most important because significant changes are manifested such as: cognition, affectivity and socialization. From the point of view of a teacher in Therapeutic Pedagogy, she stated that in this stage Special Educational Needs (Autism Spectrum Disorders, Attention Deficit Disorder and Hyperactivity Disorder, etc.) usually appear in some students, who demand more specific needs than teachers we must cover.
\end{abstract}

The main purpose of carrying out this intervention project is to develop reading comprehension in boys and girls with ADHD in the Primary Education stage through information and communication technologies, ICT from now on. In this way we will help these students to improve their reading comprehension, achieving, at the same time, greater integrity in the classroom and enhance the use of ICT.

Key words: Reading Comprehension, Attention Deficit Hyperactivity Disorder, ICT, Primary Education, attention to diver

Correspondencia

Alba Jiménez Rodríguez

albacmc18@gmail.com

Know and Share Psychology, 2(3), 61-81 


\section{INTRODUCCIÓN}

Como alumna de último curso en el grado de Educación Primaria, cuya mención es Educación Especial y futura maestra de Pedagogía Terapéutica (PT, en adelante) quiero reflejar en este trabajo de fin de grado, los conocimientos adquiridos durante esta etapa.

Esta propuesta de intervención surgió con la intención de atender al alumnado con Necesidades Específicas de Apoyo Educativo (NEAE) y cubrir las necesidades específicas que demanda. De esta forma, pienso que estoy contribuyendo a la mejora de dichas Dificultades Específicas de Aprendizaje (DEA) que puedan presentar, en este caso, alumnos con TDAH. Creo que esta iniciativa es importante, porque la mayoría de los alumnos con NEAE fracasan en sus estudios por no ser atendidos adecuadamente.

El pasado curso realicé mis segundas prácticas, concretamente las correspondientes al $4^{\circ}$ año de carrera. En ellas, tuve la fantástica oportunidad de ejercer la profesión más bonita del mundo, las cuales, se vieron afectadas por el Covid-19. Durante esa breve estancia, como docente en prácticas, observé que sólo un sujeto estaba diagnosticado con TDAH de tipo combinado. Me sorprendí mucho, era una cifra esperanzadora con respecto a otros centros escolares.

Actualmente, se considera un aumento en los casos de niños y niñas diagnosticados con TDAH, los cuales, requieren una atención personalizada donde se trabajen actividades lúdicas y unas estrategias específicas para mejorar sus dificultades y que tengan una integración de calidad dentro del aula. En esta línea, Young et ál. afirman que el TDAH "es una de las patologías psiquiátricas más ignoradas y menos conocidas. Se estima que afecta aproximadamente a uno de cada veinte niños o adolescentes en Europa" (2013, p.2)

Por otro lado, como bien menciona Espinosa "el objetivo del tratamiento es disminuir la frecuencia e intensidad de los síntomas y facilitar estrategias para su control ya que no se dispone de un tratamiento curativo en la actualidad" (2006, p.70)

Dicho esto, la realización de mi propuesta se basa en mejorar y desarrollar la comprensión lectora que tiene dicho colectivo, con la realización de actividades lúdicas a través del uso de las TIC que permitan disminuir sus dificultades, al mismo tiempo que potenciar sus habilidades.

\section{MARCO TEÓRICO}

\section{Atención a la diversidad}

Se da comienzo a este trabajo de fin de grado comentando que, actualmente, el sistema educativo lleva años luchando, y aún sigue, para que todos los centros escolares, sean lugares donde se respire inclusión, comprensión y se atienda a la diversidad. Estos términos, anteriormente nombrados, dan a entender que aunque el sistema educativo establezca unos objetivos y competencias comunes para todos los escolares, también se debe de adaptar a las necesidades específicas que presenten y demanden algunos alumnos de manera individual.

Podemos definir el concepto de Atención a la Diversidad como dar respuesta educativa a los alumnos de un centro para cubrir sus necesidades y, posteriormente, conseguir una 
inclusión educativa de calidad. Como bien indica la UNESCO (Organización de Naciones Unidas para la educación, la Ciencia y la Cultura).

A continuación, se expone una definición bastante más completa de Quiroga, la cual manifiesta que:

El concepto de diversidad nos plantea el que todos los alumnos tienen unas necesidades educativas individuales propias y específicas para poder acceder a las experiencias de aprendizaje necesarias para su socialización, establecidas en el currículo escolar. Estas necesidades educativas individuales tienen su origen en las diferencias culturales, sociales, de género y personales. Muchos alumnos experimentan dificultades de aprendizaje y de participación en la escuela porque no se tienen en cuenta dichas diferencias, como consecuencia del modelo homogeneizador de los Sistemas Educativos. (2010, p.2)

De ambas definiciones, cabe destacar, la alarmante necesidad que tienen estos alumnos de ser atendidos adecuadamente, adaptando el currículo escolar a sus necesidades. Estas necesidades surgen de múltiples factores (físicos, psicológicos y sociales). Solo de esta forma conseguiremos hablar de Educación Inclusiva y no de integración escolar.

\section{Normativa}

Tras una breve introducción de lo que significa atención a la diversidad, se da paso a realizar un recorrido de sus orígenes hasta la actualidad desde una perspectiva legislativa. A la vez, se comentarán los cambios más significativos que han ido surgiendo a lo largo del tiempo.

Todo comienza con la manifestación legislativa de la Ley de Instrucción Pública de 9 de septiembre de 1857, conocida como Ley Moyano. En esta misma línea, González Pérez comenta que "esta ley propuso la creación de una escuela para ciegos y sordos" (2009, p.249). Es decir, se ocupaba de la educación de personas con deficiencia sensorial.

Hace poco menos de un siglo, era inconcebible que las personas con Necesidades Educativas Especiales (NEE) gozaran de los mismos derechos que el resto de la sociedad en la que vivimos. Estas personas se vieron privadas de muchos derechos, entre ellos la educación. Durante varios siglos, se consideraba "persona trastornada" a aquella que padecía una anomalía o discapacidad de carácter psíquico.

Hasta los años 70 no fue posible darle un vuelco a la mentalidad española y encauzar esta hacia unas ideas más integradoras. Esta renovación de pensamientos fue posible gracias a la entrada en vigor de la Ley General de Educación 14/1970, del 6 de agosto, conocida como Ley Villar Palasí, la cual, consigue que el sistema educativo permita el nacimiento de aulas de Educación Especial en los centros ordinarios. Además, este pequeño gran cambio viene de la mano de uno de los grandes hitos de la educación; el conocido informe Warnock, publicado en 1978 en Gran Bretaña. Este cambio se consiguió tras años de lucha, donde se consiguió hablar de personas con Necesidades Educativas Especiales (NEE) y no de "personas trastornadas".

Poco a poco, la vida fue evolucionando y en 1985 se añade el término NEE en el Real Decreto de Regulación de la Educación Especial. Sin embargo, apenas cinco años más 
tarde, en 1990, aparece la Ley de Ordenación General del Sistema Educativo (LOGSE), la cual, reconoce el término de alumnos con necesidades educativas especiales (ANNE). Por último, tras duros siglos de lucha, nació el concepto que hoy en día conocemos como Necesidad Específica de Apoyo Educativo (NEAE) gracias la Ley Orgánica 2/2006, de 3 de mayo, de Educación (LOE). Dicha Ley refleja que:

La escolarización del alumnado con necesidad específica de apoyo educativo deberá estar regida por los principios de inclusión y participación, calidad, equidad, no discriminación e igualdad efectiva en el acceso y permanencia en el sistema educativo y accesibilidad universal para todo el alumnado. (2006, p. 12)

Asimismo, la LOE apuesta por:

La necesidad de que el sistema educativo dé respuesta a esta realidad social e incluya un enfoque de la competencia digital más moderno y amplio acorde con las recomendaciones europeas relativas a las competencias claves para el aprendizaje permanente. $(2006$, p. 5)

Por si fuera poco, esta ley pone de manifiesto que:

El desarrollo de la competencia digital no supone solamente el dominio de los diferentes dispositivos y aplicaciones. El mundo digital es un nuevo hábitat en el que la infancia y la juventud viven cada vez más: en él aprenden, se relacionan, consumen, disfrutan de su tiempo libre. Con el objetivo de que el sistema educativo adopte el lugar que le corresponde en el cambio digital, se incluye la atención al desarrollo de la competencia digital de los y las estudiantes de todas las etapas educativas, tanto a través de contenidos específicos como en una perspectiva transversal, y haciendo hincapié en la brecha digital de género. (2006, p. 6)

Sin embargo, no es hasta el pasado mes de diciembre cuando la LOE se ve afectada debido a la Ley Orgánica 3/2020, de 29 de diciembre, por la que se modifica la Ley Orgánica 2/2006, de 3 de mayo, de Educación. También llamada Ley Celaá.

Si se realiza una lectura comprensiva de esta nueva ley, concretamente, sobre el artículo 19.1 Principios pedagógicos, se puede observar que dicha normativa:

Garantiza la inclusión educativa: en la atención personalizada al alumnado y a sus necesidades de aprendizaje, participación y convivencia; en la prevención de las dificultades de aprendizaje y en la puesta en práctica de mecanismos de refuerzo y flexibilización, alternativas metodológicas u otras medidas adecuadas tan pronto como se detecten cualquiera de estas situaciones. (2020, p. 22)

A tal fin, esta propuesta de intervención que trabajará la competencia digital, entre otras, con sujetos diagnosticados con TDAH, se sigue viendo apoyada por la normativa actual, la conocida Ley Celaá.

A continuación, se presenta un eje cronológico destacando las Leyes reguladoras más importantes por las que ha pasado el Sistema Educativo español. 


\section{Gráfico 1}

Recorrido legislativo del sistema educativo en España.

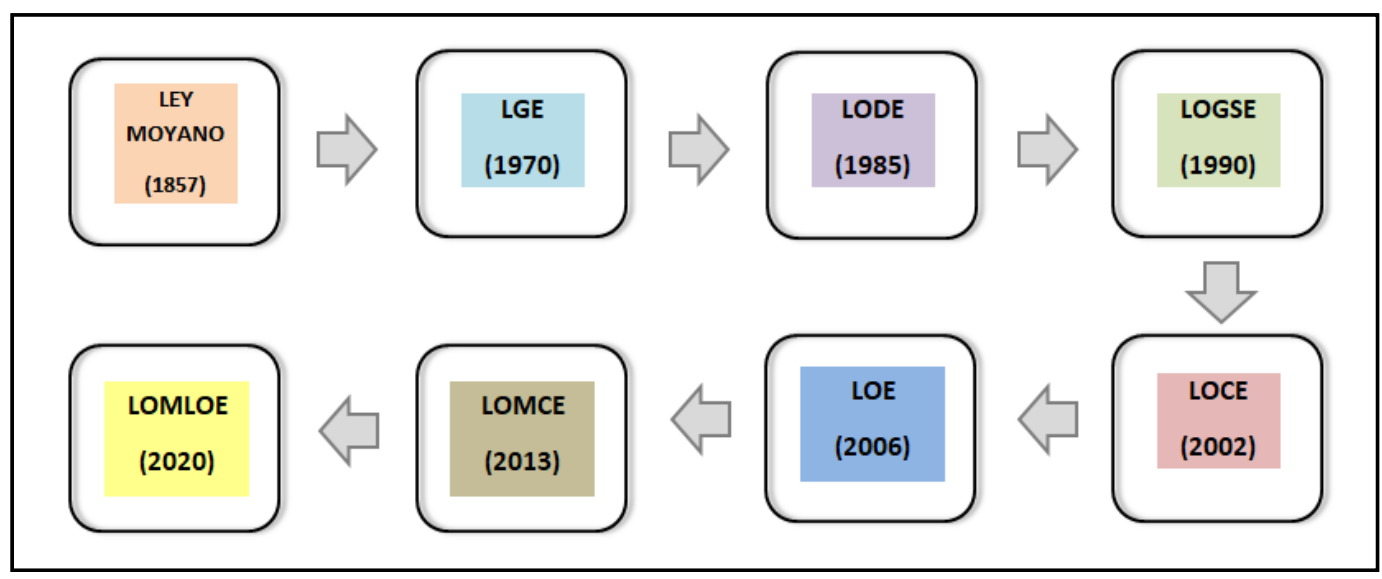

Tras leer la Orden de 15 de enero de 2021, por la que se desarrolla el currículo correspondiente a la etapa de Educación Primaria en la Comunidad Autónoma de Andalucía, se regulan determinados aspectos de la atención a la diversidad, se establece la ordenación de la evaluación del proceso de aprendizaje del alumnado y se determina el proceso de tránsito entre distintas etapas educativas.

De forma general, la relación que se extrae de dicha orden para fundamentar esta propuesta de intervención se concreta en desarrollar los conocimientos y las habilidades del alumnado para, posteriormente, aplicarlos en situaciones reales diferentes con el fin de adquirir las competencias claves a través del aprendizaje significativo. Del mismo modo, dicha orden también regula aspectos relacionados con la atención a la diversidad en Educación Primaria, apoyándose en los principios de la educación inclusiva proporcionando adaptaciones y medidas necesarias para cubrir dicha atención.

Por otro lado, si seguimos la línea que nos interesa, el área de Lengua Castellana y Literatura es vital para que los alumnos y alumnas adquieran un saber reflexivo sobre las prácticas comunicativas necesarias para vivir en la sociedad actual. Se estaría hablando de un enfoque interdisciplinar desarrollando las habilidades lingüísticas como: escuchar, hablar, dialogar, leer, escribir y de forma más específica, a la lectura y comprensión de textos. De esta forma se estaría contribuyendo a que el alumno desarrolle una de las competencias claves; la competencia lingüística o comunicativa.

Entendemos como competencia lingüística o comunicativa al conjunto de conocimientos, destrezas y actitudes necesarias para el uso de la lengua, como instrumento de expresión y comunicación, posibilitando la experiencia humana sobre la realidad y el pensamiento. No obstante, el área de Lengua Castellana y Literatura coopera en el desarrollo de la mayoría de las competencias claves, debido al carácter integrador, transversal e interdisciplinar que posee dentro del currículo. Entre ellas, aparecen: competencia en comunicación lingüística (CCL), competencia digital (CD), competencia de aprender a aprender (CAA), competencias sociales y cívicas (CSC), 
sentido de iniciativa y espíritu emprendedor (SIEP) y conciencia y expresiones culturales (CEC).

Si aludimos al título de esta propuesta, es necesario destacar la competencia digital, ya que es uno de los objetivos específicos de dicho trabajo. La anexión de esta competencia a esta área hace posible el uso de soportes electrónicos para desarrollar diversas destrezas saliéndose del aprendizaje tradicional, es decir, utilizando una estrategia de carácter innovador.

\section{Trastorno por déficit de atención e hiperactividad}

Antes de adentrarnos en hablar sobre el Trastorno por déficit de atención e hiperactividad debemos aclarar varios conceptos bastante importantes, para saber situar este trastorno Nos preguntaremos, si existe diferencia entre un alumno con NEE y un alumno con NEAE. Por ello, debemos establecer ciertas discrepancias para poder entender ambos conceptos. Según CNREE (1992, como se citó en Jiménez Sánchez, 2001) se entiende que un alumnado tiene NEE:

Cuando presenta mayores dificultades que el resto del alumnado para acceder a los aprendizajes que se determinen en el currículo que le corresponde para su edad, bien sea por causas internas, dificultades o carencias en el entorno sociofamiliar (...) y necesitan para compensar las dificultades adaptaciones de acceso (AAC) y/o adaptaciones curriculares individuales (ACI) en una o varias áreas del currículo. (p. 170)

Posteriormente, como ya hemos comentado en párrafos anteriores, con la llegada de la LOE se introduce el término de necesidades específicas de apoyo educativo (NEAE). Este concepto incorpora al alumnado que manifiesta necesidades educativas especiales, dificultades específicas de aprendizaje, altas capacidades intelectuales, incorporación tardía al sistema educativo, o condiciones derivadas de situaciones personales o por su historia escolar

Más tarde, la Ley Orgánica 8/2013, de 9 de diciembre, para la mejora de la calidad educativa (LOMCE) considera que el alumnado con NEE, con dificultades específicas de aprendizaje, TDAH, altas capacidades intelectuales, de incorporación tardía al sistema educativo, etc. Se incluyan dentro del concepto de NEAE.

Sin embargo, cabe cuestionar, qué es el Trastorno por déficit de atención e hiperactividad. Pues bien, a lo largo de la historia han sido numerosas las definiciones que se le han dado a este trastorno. Este recorrido histórico se puede esquematizar de la siguiente forma: 


\section{Tabla 1}

Numerosas definiciones de TDAH a lo largo de la historia

\begin{tabular}{|l|l|l|}
\hline Autor & An̂o & Termino \\
\hline Hoffman & 1845 & $\begin{array}{l}\text { Primero en describir el comportamiento de niños } \\
\text { hiperactivos en el libro infantilStruwwelpeter. }\end{array}$ \\
\hline Bournerville & 1887 & Describe a niños inestables \\
\hline J.Demoor & 1901 & $\begin{array}{l}\text { Describe a niños muy hábilescomportamentalmente, } \\
\text { con dificultades atencionales. }\end{array}$ \\
\hline Still & 1902 & $\begin{array}{l}\text { Niños con discapacidad en la fuerza de voluntad. } \\
\text { Defectos del control moral }\end{array}$ \\
\hline $\begin{array}{l}\text { Hohman, Kant, } \\
\text { Cohen }\end{array}$ & 1934 & Sindrome de lesión cerebral humana. \\
\hline ClementsyPeters & 1962 & Sindrome de disfunción cerebral mínima. \\
\hline DSM II & 1968 & Reacciónhiperkinéticade la infancia. \\
\hline DSM III & 1980 & Déficit de atención con y sin hiperactividad. \\
\hline OMS & 1992 & Trastornohipercinético(CIE-10) \\
\hline DSM IV & 1994 & $\begin{array}{l}\text { Déficit de atención con hiperactividad. } \\
\text { Se introducen tres subtipos. }\end{array}$ \\
\hline Barkley & 1997 & Déficit en el control inhibitorio \\
\hline
\end{tabular}

Fuente: Concepto, evolución y etiología del TDAH. (Fernandes, Piñón Blanco y Vázquez-Justo, 2017, p.5)

A raíz de este esquema, por un lado, Barkley (1990, como se citó en Fernandes et ál., 2017) considera que el Trastorno por déficit de atención e hiperactividad (TDAH, en adelante) "es un trastorno del neurodesarrollo, con base genética y elevada heredabilidad, en el que se hallan implicados diversos factores neuropsicológicos, que provocan en el niño alteraciones de la atención, impulsividad y sobreactividad motora" (p. 3). El tema es de interés en el ámbito psiquiátrico. Descubrimos que Lin Chin et al, (2021) han realizado una revisión bibliográfica sistemática acerca de este trastorno en la que destacan cien estudios. Además, hay un programa reciente para la rehabilitación de la atención para estos niños (Nejati, 2021).

Por otro lado, Casas y Ferrer definen el TDAH como "un patrón persistente de desatención y/o hiperactividad-impulsividad, que es más frecuente y grave que el observado habitualmente en sujetos de un nivel de desarrollo similar" (2010, p. 100).

En la misma línea, Pollanczyk G et ál. (2007, como se citó en Hidalgo, 2014) comenta que "el TDAH es un trastorno neurobiológico y afecta al 2-12\% de la población pediátrica mundial” (p. 595).

Por tanto, podemos entender que el TDAH es un trastorno neurobiológico que se caracteriza por déficit de atención, hiperactividad, es decir, excesiva actividad e impulsividad. Al mismo tiempo, como postula González "se considera trastorno cuando hay una alta frecuencia e intensidad y, además, interfiere en la vida diaria del sujeto" (2018, p. 631).

\section{Know and Share Psychology, 2(3), 61-81}


Por consiguiente, estos niños presentan dificultades en el proceso de aprendizaje. Al respecto González añade que:

Todo esto conlleva graves dificultades en el control del tiempo, en la planificación y organización, en la persistencia ante la realización y finalización de una tarea, en el seguimiento de las normas, en la motivación, en la memoria de trabajo y en otras funciones. (2018, p.632)

En este sentido, estimar con precisión la importancia de este trastorno por la envergadura de casos que nos encontramos en las aulas, según Catalá-López et ál. (2012, como se citó en González, 2018) expone que:

En España, a través de una revisión sistemática y metaanálisis de 14 estudios, que incluían un total de 13.023 niños y adolescentes, se ha estimado una prevalencia global del 6,8\%, siendo mayor en varones que en mujeres. (p. 595)

Del mismo modo, Artigas (2003) y Kessler (2004) citado por Gómez et ál. (2009) señalan que:

Dicho trastorno, se presenta en la mayoría de los casos con otros trastornos comórbidos, hasta un $70 \%$ de estos niños padecen otros trastornos asociados como pueden ser, por ejemplo: alteraciones del lenguaje, dificultad para el aprendizaje, trastorno de ansiedad y del ánimo, trastornos negativistas desafiante y de conducta y tics. Por todo ello, una persona con TDAH tiene 6 veces más probabilidades de padecer otro trastorno psiquiátrico asociado, empeorando de este modo tanto el diagnóstico como su evolución, así como la respuesta al tratamiento. (p. 66)

En definitiva, Berkley (2002, como se citó en González, 2018) apunta que "sólo entre el $5 \%$ y el $10 \%$ de los alumnos con TDAH acaba sus estudios universitarios, siendo los dos primeros años los momentos más críticos para el abandono de dichos estudios debido al sustancial cambio que experimentan" (p. 632).

Así pues, es vital saber que, el TDAH forma parte de la clasificación de los diferentes Trastornos Graves de Conducta. Según el manual de la Consejería de Educación de la Junta de Andalucía a las personas que manifiestan trastornos graves de conducta merecen una atención profesional específica:

Deben recibir determinados apoyos y atenciones educativas específicas, que deben abordarse desde un enfoque interdisciplinario y sistémico en el cual intervengan diferentes servicios, instituciones u organismos e implicando a la comunidad educativa, especialmente a la familia, la cual también necesita de apoyo personal y social para superar las situaciones de estrés y disponer de orientaciones claras que le permitan comprender y dar respuesta a las necesidades de su hijo o hija. (2008, p. 7)

Como ya se ha comentado en líneas anteriores, el TDAH está caracterizado por: desatención, debido a una disminución del espectro de la atención. Impulsividad conductual y cognoscitiva, es decir, estos niños presentan dificultad para inhibir las 
respuestas e hiperactividad motora, verbal y conductual. Estos trastornos, dependiendo de los síntomas que presenten, se definen en tres subtipos:

- $\mathrm{TDA} / \mathrm{H}$ con presentación predominante con falta de atención.

- $\mathrm{TDA} / \mathrm{H}$ con presentación predominante hiperactiva/impulsiva.

- $\mathrm{TDA} / \mathrm{H}$ con presentación combinada.

Estos subtipos vienen acompañados de diferentes síntomas y niveles de gravedad: leve, moderado o grave. A continuación, se muestran los diferentes síntomas que pueden aparecer, dependiendo del subtipo de TDAH que se manifieste:

- síntomas con presentación predominante en falta de atención.

Tabla 2.

Sintomas del TDAH con predominancia en falta de atención

\begin{tabular}{|c|}
\hline Falta de atención \\
\hline No mantienen el mismo grado de compromiso en las tareas que otros niños. \\
\hline Presentan dificultades para prestar atención suficiente a los detalles. \\
\hline Parecen no escuchar. \\
\hline Tienen dificultades para organizar las tareas y no suelen finalizarlas. \\
\hline Evitan el esfuerzo mental sostenido. \\
\hline Pierden objetos. \\
\hline Se distraen por estímulos irrelevantes. \\
\hline Son olvidadizos. \\
\hline
\end{tabular}

Fuente: Déficit de atención con hiperactividad (TDAH): Concepto, características e intervención educativa. (Ariza, 2010, p. 2)

- síntomas con presentación predominante en hiperactividad/impulsividad

\section{Tabla 3}

Síntomas del TDAH con predominancia en hiperactividad

\begin{tabular}{|c|} 
Hiperactividad \\
\hline Hablan en exceso y sin control. \\
\hline Mueven constantemente manos y pies. \\
\hline Abandonan el asiento de la clase. \\
\hline Corren o saltan en situaciones inapropiadas. \\
\hline Dificultad para jugar de forma calmada \\
\hline Actúan como si estuvieran impulsados por un motor. \\
\hline
\end{tabular}


Es más común en niños preescolares, siendo posiblemente, el precursor evolutivo del subtipo combinado.

Fuente: Déficit de atención con hiperactividad (TDAH): Concepto, características e intervención educativa. (Ariza, 2010, p. 2)

- síntomas con presentación combinada: presentan una mezcla de síntomas de falta de atención y de hiperactividad e impulsividad. Esto hace que existan problemas más severos afectando al comportamiento y al aprendizaje del sujeto.

\section{Tabla 4}

Sintomas del TDAH con predominancia en impulsividad

\begin{tabular}{|c|}
\hline Impulsividad \\
\hline Responden de forma precipitada a las preguntas. \\
\hline Tienen dificultades para guardar su turno. \\
\hline Interrumpen a otros. \\
\hline
\end{tabular}

Fuente: Déficit de atención con hiperactividad (TDAH): Concepto, características e intervención educativa. (Ariza, 2010, p. 3)

Por un lado, en cuanto a la intervención educativa en la escuela, el centro está formado por profesionales, los cuales, de manera conjunta hacen frente a la respuesta educativa del discente. Como bien afirma Galve Manzano, el alumnado con TDAH "deben recibir atención tanto dentro como fuera del aula (enfoque multidisciplinar) con intervenciones desde las perspectivas médicas, psicológicas y psicopedagógicas” (2010, p. 87). Por este motivo, el alumno con TDAH debe ser tratado correctamente. De lo contrario, su evolución académica puede llegar a verse gravemente afectada provocando el fracaso escolar, entre otros problemas. De ahí que, padres o tutores del niño y profesores requieran de la formación suficiente para saber cómo y cuándo deben intervenir, pautas, estrategias, etc. Por otro lado, estamos de acuerdo con Sevilla y Garrido en que "los tratamientos que de manera más frecuente se utilizan en la escuela son los de modificación de conducta, los tratamientos cognitivo-conductuales y los tratamientos psicopedagógicos" (2004, p. 156).

\section{La comprensión lectora en alumnos con TDAH}

Para abordar este apartado, consideramos de vital importancia el concepto de lectura y el rol que ejerce en la sociedad. El término lectura para la Real Academia Española (en adelante RAE) es "la acción de leer". Si profundizamos más, la RAE define leer como "pasar la vista por lo escrito o impreso comprendiendo la significación de los caracteres empleados". Este concepto ha originado muchas definiciones por diversos autores, las cuales, se muestran a continuación.

Montealegre (2004, como se citó en Morales y Ramos, 2014) considera el concepto de lectura como "un proceso complejo ya que implica diversos recursos cognitivos que hacen que la comprensión de lo leído se desarrolle adecuadamente y permita la adquisición de nuevos aprendizajes, al reconocer, identificar y codificar la información 
relevante de los textos" (p. 453). Esta descripción da a entender que la acción de leer lleva implícito el término comprender. De ahí, lo que conocemos como comprensión lectora. Además, Morales y Ramos argumentan que "la comprensión lectora requiere de la interacción de diversos procesos cognitivos: atención, percepción, memoria y conciencia fonológica; estos procesos permiten detectar dificultades en el desarrollo cognoscitivo infantil" (2014, p. 452).

Los niños con TDAH, dependiendo del subtipo que padezcan, carecen de unos aspectos cognoscitivos u otros. La Asociación Americana de Psiquiatría y la Clasificación Internacional de Trastornos Mentales de la Organización de la Salud (como se citó en Abad-Mas et ál., 2013) manifiestan que "la sintomatología básica engloba problemas atencionales, de hiperactividad y de impulsividad, y se distinguen tres subtipos de TDAH" (p. 194). Estos subtipos son los que nombramos y desarrollamos en el apartado 2.2 Trastorno por déficit de atención e hiperactividad (inatención, hiperactividad e impulsividad). Por lo tanto, dependiendo del subtipo de TDAH que tenga el sujeto, se manifestarán unos síntomas u otros.

Como bien se comenta al principio de esta propuesta, desde una perspectiva de acción como docente en pedagogía terapéutica, se encauza dicha intervención en trabajar el ámbito cognitivo-académico, cuyo objetivo principal radica en estimular, desarrollar y mejorar la comprensión lectora en niños con TDAH a través de las TIC.

\section{TDAH y TIC}

La enorme expansión del desarrollo de las tecnologías de la información y la comunicación (TIC, en adelante) ha generado significativos cambios en la sociedad e indudablemente en el ámbito educativo. Como bien expresa González las TIC "han demostrado ser un recurso educativo con capacidad para complementar, enriquecer y transformar el proceso de enseñanza y aprendizaje" (2018, p. 632). Asimismo, Crook (1998, como se citó en Latorre-Cosculluela et ál., 2018) afirma que "el aprendizaje cooperativo apoyado en recursos tecnológicos ha sido considerados como un enfoque educativo de gran eficacia" (p. 145). En la misma línea de lo expuesto anteriormente, Muntaner (2005, como se citó en González, 2018) añade que "las tecnologías suponen una gran ayuda como medio para individualizar la enseñanza, acceder al currículum, facilitar el aprendizaje, como reforzador didáctico y como herramienta imprescindible para la labor docente" (p. 633).

Autores como Latorre-Cosculluela et ál. argumentan que "el incremento del uso de dispositivos tecnológicos durante las tareas de aprendizaje cooperativo puede mejorar la participación de los estudiantes con dificultades de aprendizaje y eludir las barreras específicas que, habitualmente, vienen asociadas con la necesidad educativa" (2018, p. 143). Es relevante incorporar diversas TIC al área de Lengua en combinación con metodologías activas en Educación Primaria para promover la comunicación lingüística (Peña-Acuña, 2019; Peña-Acuña, 2020).

En resumen, la integración de las TIC dentro del aula juega un papel bastante importante. Aparte de ser un recurso totalmente innovador en el sistema educativo, también actúa como herramienta esencial y complementaria en la formación y aprendizaje de los alumnos. De esta forma, se reduciría el fracaso escolar, 
especialmente, en aquellos alumnos que tienen Necesidades Especificas de Apoyo Educativo (NEAE).

Tras esta reflexión, se ha realizado una investigación sobre algunos programas informáticos, cuya función es mejorar la comprensión lectora de los discentes. Estos son los conocidos como MeMotiva, Piruletras, EducaPlay, Kahoot, ExeLearning, Quiz Revolution, Kubbu, Celebrity, etc... Más adelante, se hablará de los más importantes que se tendrán en cuenta para diseñar esta intervención.

Finalmente, si se tiene en cuenta todos los factores expuestos anteriormente, de algún modo u otro, justifica la iniciativa de esta propuesta de intervención; trabajar la comprensión lectora en alumnos con TDAH a través de las TIC.

\subsection{Aplicaciones y programas informáticos para alumnos con TDAH}

En este apartado, por un lado, se presentan varios programas informáticos; MeMotiva y Piruletras, y, por otro lado, diversas plataformas online como son EducaPlay y Kahoot. Todas estas aplicaciones informáticas son ideales para trabajar y fomentar la comprensión lectora en el alumnado con TDAH. Sin embargo, es importante señalar que MeMotiva y Piruletras trabajan el objetivo general de esta propuesta de intervención, mientras que, EducaPlay y Kahoot se centran en trabajar los objetivos específicos de dicha propuesta. A continuación, se detallan cada uno de ellos. MeMotiva

\section{MeMotiva}

Es un programa diseñado para aumentar la capacidad de la memoria operativa en niños y adultos con dificultades de atención y concentración. Está especialmente indicado para niños con TDAH. Si el sujeto diagnosticado de TDAH utiliza este programa tecnológico encontrará beneficios en siguientes aspectos como disminuir su impulsividad, aumento de la atención focalizada y sostenida, aumento de la capacidad de la memoria a corto plazo, mejora de la comprensión de textos, es decir, la comprensión lectora, etc.

\section{Piruletras}

Piruletras es una divertida aplicación de carácter gratuita basada en el juego y diseñada para mejorar la lectura y escritura en los niños con TDAH que padecen dislexia. Este juego organiza los contenidos en cinco niveles: inicial, fácil, medio, difícil y experto. Además, cuenta con un total de 2.500 ejercicios diferentes, los cuales, serán de seis tipos diferentes: omisión, sustitución, inserción, derivación, transposición y separación de palabras.

\section{EducaPlay}

EducaPlay es una plataforma para la creación de actividades educativas multimedia, la cual, permite crear de forma muy sencilla las actividades con un resultado atractivo y profesional. Con esta plataforma se puede diseñar diferentes tipos de actividades como por ejemplo: mapas, adivinanzas, completar textos, crucigramas, diálogo, dictado, ordenar letras, ordenar palabras, relacionar con flechas, sopas de letras, test, etc. 


\section{Kahoot}

Kahoot es una plataforma gratuita que permite la creación de cuestionarios. El profesor crea concursos en el aula para aprender o reforzar el aprendizaje y donde los alumnos son los concursantes. Se puede jugar en grupo o individual. Las partidas de preguntas, una vez creadas, son accesibles por todos los usuarios de manera que pueden ser reutilizadas e incluso modificadas para garantizar el aprendizaje. Se puede modificar el tiempo de cuenta atrás, las posibles respuestas y se pueden añadir fotos o vídeos. Finalmente gana quien obtiene más puntuación. Esta propuesta de intervención trabajará los objetivos específicos con las plataformas EducaPlay y Kahoot, ya que son las que mejor se ajustan y más variedad de creación de actividades ofrece.

\section{CONTEXTUALIZACIÓN DEL PROYECTO}

\section{Descripción del entorno y del centro.}

El C.E.I.P Sánchez Arjona pertenece a la localidad de Paterna del Campo (Huelva). Es un pueblo situado al Este de la Provincia Onubense, con una extensión de $132.44 \mathrm{~km}^{2}$, y a una distancia de la capital de sesenta y dos $\mathrm{km}$. En la actualidad, cuenta con una población de derecho de tres mil ochocientos habitantes, siendo prácticamente en su totalidad naturales de la localidad.

La principal actividad económica de sus habitantes es la agricultura. Los principales cultivos son los siguientes: cereales, algodón, remolacha y garbanzos. Un sector menor de la población se dedica a las actividades empresariales y servicios, entre otros: la construcción, el transporte, el comercio y los talleres de reparación de vehículos de motor. El tipo de vivienda que predomina en el pueblo es unifamiliar, de tipo mediterráneo, estando en su gran mayoría bien acondicionadas.

No obstante, existe en la periferia, un barrio marginal cuyos habitantes tienen un nivel socioeconómico y cultural bajo. La tasa de analfabetismo cada vez es menor, centrándose en la actualidad en personas de avanzada edad.

Este municipio cuenta con cuatro centros educativos públicos: una escuela infantil, que acoge a niños desde cero a dos años; un colegio de educación infantil y primaria, un I.E.S., donde se imparte ESO y Bachillerato y un centro de educación de adultos.

\section{Destinatarios.}

Esta población serán sujetos pertenecientes al primer ciclo de la etapa de Educación Primaria, es decir, alumnos y alumnas de entre seis y ocho años que hayan sido previamente diagnosticados de TDAH. Actualmente, el centro donde se llevará a cabo esta propuesta de intervención solo cuenta con un alumno diagnosticado con TDAH de tipo combinado. 


\section{OBJETIVOS}

\section{Objetivo general}

- Fomentar la comprensión lectora en niños y niñas con TDAH a través de las TIC.

\section{Objetivos específicos}

- Realizar actividades de carácter lúdico y textos escritos didácticos a niños con TDAH para mejorar la comprensión lectora utilizando las TIC.

- Identificar y extraer la idea principal de textos escritos a través de las TIC.

\section{Competencias y contenidos}

Las competencias básicas que se trabajan en esta propuesta de intervención educativa cuya finalidad es favorecer la adquisición de ciertas habilidades son las siguientes: autonomía e iniciativa personal, social y ciudadana, comunicación lingüística, conocimiento e interacción con el mundo físico, aprender a aprender y, por último, competencia digital.

Por otro lado, los contenidos que se trabajarán en este proyecto han sido extraídos del área de Lengua Castellana y Literatura correspondiente al anexo II de la Orden de 15 de Enero de 2021, emitido por la Junta de Andalucía, que, a su vez, sigue las indicaciones de la Ley Celáa (2020). Estos contenidos se pueden consultar desde la página 81 en anexo II de esta Orden.

\section{METODOLOGÍA}

La metodología que se aplicará es con carácter activo, con el fin de que el alumnado, mediante juegos lúdicos a través de las TIC, sea el protagonista de las actividades que llevará a cabo dentro del aula, aunque se debe tener en cuenta el siguiente matiz. Según Romero Pérez (2004, como se citó en Millán, 2012) señala que "los alumnos con TDAH tienen grandes dificultades para procesar más de un aspecto a la vez además de una clara falta de concentración" (p. 6). De modo que "cada alumno es diferente y dependiendo del grado de actuación de la enfermedad, los docentes podrán intervenir en mayor o menor medida" (p. 6). Ambos autores pretenden transmitir que aunque el alumno o la alumna sea el protagonista de su actividad, el docente deberá intervenir más o menos veces dependiendo del grado de afectación que manifieste su enfermedad.

Esta metodología es lúdica y gamificada, ya que presume por ser atractiva e innovadora, así como divertida, indagadora y motivadora para atraer la atención de los alumnos y alumnas con TDAH. Paralelamente, desarrolla la creatividad e imaginación de dichos sujetos. 


\section{PROPUESTA DE INTERVENCIÓN}

La tabla que se muestra a continuación presenta treinta actividades lúdicas e interactivas, utilizando recursos digitales (plataformas) con el objetivo de trabajar, de forma innovadora, la comprensión lectora con el alumnado con TDAH a través de las TIC. El nivel de complejidad de dichas actividades es fácil, ya que están enfocadas para alumnos de $1^{\circ}$ ciclo de primaria, los cuales tienen Necesidades Específicas de Apoyo Educativo (NEAE). Además, son adaptables a las necesidades y características de cada alumno. Esta propuesta de intervención será realizada por la maestra PT en el aula de Educación Especial.

\begin{tabular}{|c|c|}
\hline ACTIVIDAD 1 & $\begin{array}{l}\text { Leer las frases del recuadro y adivinar con qué objeto o comida se } \\
\text { queda. Debe comprender cada oración para escribir el nombre } \\
\text { correcto. (Anexo 1) }\end{array}$ \\
\hline ACTIVIDAD 2 & $\begin{array}{l}\text { Unir con flechas cada oración con su correspondiente dibujo. El } \\
\text { alumno debe leer cada acción y relacionarla con el dibujo correcto } \\
\text { (Anexo 2) }\end{array}$ \\
\hline ACTIVIDAD 3 & $\begin{array}{l}\text { Observar cada imagen y señalar el objeto que no concuerde con los } \\
\text { demás. El alumno debe observar atentamente la imagen y deducir } \\
\text { qué objeto no tiene nada que ver con el resto. (Anexo 3) }\end{array}$ \\
\hline ACTIVIDAD 4 & $\begin{array}{l}\text { Leer y seguir los pasos en cada caso. Se trata de una actividad donde } \\
\text { se presentan formas geométricas y otras figuras y el alumno debe } \\
\text { hacer lo que la frase ordena. (Anexo 4) }\end{array}$ \\
\hline ACTIVIDAD 5 & $\begin{array}{l}\text { Observar la imagen y responder en la tabla verdadero o falso con } \\
\text { respecto a cada oración. El alumno debe mirar la imagen y } \\
\text { comprobar si lo que dice la oración es cierto o no. (Anexo 5) }\end{array}$ \\
\hline ACTIVIDAD 6 & $\begin{array}{l}\text { Leer las frases y decir si es verdadero o falso. En esta actividad se } \\
\text { presenta una serie de oraciones con una imagen cada una de ellas. } \\
\text { El alumno debe leer detenidamente cada frase para ver si se } \\
\text { corresponde con la imagen o no. A continuación, debe responder } \\
\text { con verdadero o falso. (Anexo 6) }\end{array}$ \\
\hline ACTIVIDAD 7 & $\begin{array}{l}\text { Leer las oraciones y marcar la que sea correcta con respecto a la } \\
\text { imagen. (Anexo 7) }\end{array}$ \\
\hline ACTIVIDAD 8 & $\begin{array}{l}\text { Leer las frases y observar las imágenes que se presentan. Luego } \\
\text { responder si es verdadero o falso. El alumno debe leer y observar } \\
\text { detenidamente para elegir la correcta. (Anexo 8) }\end{array}$ \\
\hline
\end{tabular}

Know and Share Psychology, 2(3), 61-81 


\begin{tabular}{|c|c|}
\hline ACTIVIDAD 9 & $\begin{array}{l}\text { Completar las siguientes oraciones con las palabras que se muestran } \\
\text { en la caja. El alumno debe crear oraciones con sentido, leyendo y } \\
\text { comprendiendo para colocar cada palabra en el hueco correcto. } \\
\text { (Anexo 9) }\end{array}$ \\
\hline ACTIVIDAD 10 & $\begin{array}{l}\text { Leer y seguir las diversas indicaciones que se piden. El alumno } \\
\text { tiene que leer y observar cada imagen para realizar la actividad } \\
\text { correctamente. (Anexo 10) }\end{array}$ \\
\hline ACTIVIDAD 11 & $\begin{array}{l}\text { Leer detenidamente el siguiente texto y marcar la respuesta correcta } \\
\text { con respecto al texto y la imagen. El alumno debe comprender el } \\
\text { texto para poder responder bien. (Anexo 11) }\end{array}$ \\
\hline ACTIVIDAD 12 & $\begin{array}{l}\text { Leer cada texto y completar la tabla, organizando los personajes, el } \\
\text { lugar donde ocurre la historia y los objetos que aparecen. Se } \\
\text { presentan tres minitextos y el alumno debe extraer las ideas } \\
\text { principales de cada uno de ellos. (Anexo 12) }\end{array}$ \\
\hline ACTIVIDAD 13 & $\begin{array}{l}\text { Realizar lectura comprensiva de la siguiente historia y señalar la } \\
\text { secuencia de imágenes que sea correcta. Se muestra un texto y una } \\
\text { serie de secuencias a través de imágenes. El alumno que realice esta } \\
\text { actividad deberá señalar la secuencia correcta con respecto a la } \\
\text { historia presentada. (Anexo 13) }\end{array}$ \\
\hline ACTIVIDAD 14 & $\begin{array}{l}\text { Observar la siguiente imagen y responder correctamente cada } \\
\text { pregunta en relación con la imagen. (Anexo 14) }\end{array}$ \\
\hline ACTIVIDAD 15 & $\begin{array}{l}\text { Leer atentamente cada texto y rodear la imagen correcta con } \\
\text { respecto a dicho texto. El alumnado debe leer atentamente y señalar } \\
\text { la imagen correcta. (Anexo 15) }\end{array}$ \\
\hline ACTIVIDAD 16 & $\begin{array}{l}\text { Leer el siguiente texto y responder la batería de preguntas que se } \\
\text { exponen. Los alumnos deben realizar una lectura comprensiva para } \\
\text { poder responder cada pregunta favorablemente. (Anexo 16) }\end{array}$ \\
\hline ACTIVIDAD 17 & $\begin{array}{l}\text { Leer atentamente el texto y marcar la respuesta correcta. Se muestra } \\
\text { una imagen para facilitar la actividad. (Anexo 17) }\end{array}$ \\
\hline ACTIVIDAD 18 & $\begin{array}{l}\text { Observar las dos imágenes y marcar las afirmaciones correctas con } \\
\text { respecto a cada una de ellas. El alumno debe leer y fijarse bien en } \\
\text { la foto para realizar correctamente la actividad. (Anexo 18) }\end{array}$ \\
\hline ACTIVIDAD 19 & $\begin{array}{l}\text { Leer cada definición detenidamente y relacionarla con la imagen } \\
\text { correspondiente. (Anexo 19) }\end{array}$ \\
\hline ACTIVIDAD 20 & $\begin{array}{l}\text { Buscar palabras en la siguiente sopa de letras. Se da una pequeña } \\
\text { pista a través de imágenes y la primera letra de cada palabra } \\
\text { marcada. (Anexo 20) }\end{array}$ \\
\hline
\end{tabular}




\begin{tabular}{|c|c|}
\hline ACTIVIDAD 21 & $\begin{array}{l}\text { Leer atentamente cada oración y rellenar cada hueco con la palabra } \\
\text { correcta. Para ello, se muestra una caja con diferentes palabras, las } \\
\text { cuales, corresponde con una de las oraciones presentadas. (Anexo } \\
\text { 21) }\end{array}$ \\
\hline ACTIVIDAD 22 & $\begin{array}{l}\text { Realizar lectura comprensiva de la historia ¡Nos vamos de viaje! y } \\
\text { responder verdadero o falso en cada una de las oraciones. (Anexo } \\
\text { 22) }\end{array}$ \\
\hline ACTIVIDAD 23 & $\begin{array}{l}\text { Realizar lectura comprensiva de la historia ¡El día a día de Fabián! } \\
\text { Para poder marcar las oraciones que sean correctas con respecto al } \\
\text { texto presentado. (Anexo 23) }\end{array}$ \\
\hline ACTIVIDAD 24 & $\begin{array}{l}\text { Relacionar cada frase con la imagen adecuada. El alumno debe } \\
\text { relacionar las fotos con sus correctas definiciones (Anexo 24) }\end{array}$ \\
\hline ACTIVIDAD 25 & $\begin{array}{l}\text { Escribir cuatro oraciones correctas sobre la imagen presentada } \\
\text { (Anexo 25) }\end{array}$ \\
\hline ACTIVIDAD 26 & $\begin{array}{l}\text { Realizar lectura comprensiva de cada mini historia y señalar la } \\
\text { imagen correcta con respecto al texto anteriormente leído. (Anexo } \\
\text { 26) }\end{array}$ \\
\hline ACTIVIDAD 27 & $\begin{array}{l}\text { Realizar lectura comprensiva de las siguientes oraciones y elegir la } \\
\text { respuesta correcta para que dichas oraciones tengan coherencia. } \\
\text { (Anexo 27) }\end{array}$ \\
\hline ACTIVIDAD 28 & $\begin{array}{l}\text { Realizar lectura comprensiva de cada oración y responder a todas } \\
\text { las preguntas. (Anexo 28) }\end{array}$ \\
\hline ACTIVIDAD 29 & $\begin{array}{l}\text { Realizar lectura comprensiva de la siguiente historia presentada } \\
\text { para poder marcar las oraciones que sean correctas con respecto a } \\
\text { dicha historia. (Anexo 29) }\end{array}$ \\
\hline ACTIVIDAD 30 & $\begin{array}{l}\text { Leer atentamente cada oración y extraer de cada una de ellas los } \\
\text { personajes, el lugar donde se desarrolla y los objetos que aparecen. } \\
\text { (Anexo 30) }\end{array}$ \\
\hline
\end{tabular}

\section{RECURSOS, PRESUPUESTO Y TEMPORALIZACIÓN}

El recurso más importante utilizado en esta propuesta de intervención es el recurso digital, es decir, el uso del ordenador o tableta para poder llevar a cabo las actividades previstas. También será necesario el uso de una pizarra digital y un proyector. Además, para que dichas actividades sean aún más atractivas, se emplea el uso de imágenes, y sonido en alguna ocasión, con la finalidad de adquirir mejor los conocimientos. 
El presupuesto contemplado para dicha propuesta es el siguiente:

Tabla 5. Presupuesto de la propuesta de intervención

\begin{tabular}{|l|l|l|l|}
\hline \multicolumn{1}{|c|}{ Gastos } & Precio & \multicolumn{1}{c|}{ Unidad/es } & Coste \\
\hline \multicolumn{1}{|c|}{ A. Personal } & & & \\
\hline & & & \\
\hline \multicolumn{1}{|c|}{ B. Materiales } & & & \\
\hline Ordenador portátil & & Propio del centro & \\
\hline Tableta Huawei 15” & $139,00 €$ & \multicolumn{1}{c|}{2} & $278,00 €$ \\
\hline Pantalla digital & & Propio del centro & \\
\hline Proyector & & Propio del centro & \\
\hline & & $\begin{array}{l}\text { TOTAL } \\
\text { GASTOS }\end{array}$ & $278,00 €$ \\
\hline
\end{tabular}

Fuente: elaboración propia

Tras detallar los materiales necesarios para llevar a cabo este proyecto, el precio del presupuesto, en cuanto al uso de los tics, es muy asequible. Asimismo, las aplicaciones digitales empleadas son totalmente gratuitas, solo es necesario registrarse con un correo electrónico para poder acceder y, de este modo, quede almacenado todos los diseños que se hagan.

Referente a la temporalización del proyecto, la duración será aproximadamente de dos meses, en los cuales dos días a la semana se trabajará la comprensión lectora, siendo el total unas quince sesiones de cuarenta y cinco minutos. Cada semana se realizarán cuatro actividades (depende del ritmo, nivel de comprensión de cada alumno, etc.). No obstante, hay que tener en cuenta, que al trabajar con alumnos con TDAH, se necesita más tiempo para que se calmen y poder comenzar la actividad. Es decir, cada alumno tiene su ritmo y hay que adaptarse a él.

\section{Tabla 6}

Cronograma de actividades

\begin{tabular}{|c|c|c|}
\hline \multirow{2}{*}{$N^{o}$ de semana } & Día 1 & Déa 2 \\
\cline { 2 - 3 } Semana 1 & 1 y 2 & 3 y 4 \\
\hline Semana 2 & 5 y 6 & 7 y 8 \\
\hline Semana 3 & 9 y 10 & 11 y 12 \\
\hline Semana 4 & 13 y 14 & 15 y 16 \\
\hline Semana 5 & 17 y 18 & 19 y 20 \\
\hline Semana 6 & 21 y 22 & 23 y 24 \\
\hline Semana 7 & 25 y 26 & 27 y 28 \\
\hline
\end{tabular}




\section{Semana 8}

\section{9 y 30}

Tabla 6. Fuente: elaboración propia

\section{EVALUACIÓN DE RESULTADOS}

En cuanto a la evaluación de resultados, por un lado, se realizará una rúbrica dirigida al alumnado acerca de si le ha gustado esta programación y qué han aprendido (Anexo 39). Por otro lado, se llevará a efecto otra rúbrica de mejora enfocada a la propia intervención, con la finalidad de diagnosticar y corregir posibles errores de este proyecto. De esta manera, se adaptará mejor a las necesidades de los diversos alumnos (Anexo 40). Asimismo, como esta propuesta destaca por su carácter innovador, dichas evaluaciones y rúbricas serán efectuadas a través de encuestas online, es decir, se empleará el uso de las TIC para llevarlas a cabo. Así, quedarán todos los datos almacenados de forma digital.

Por último, es necesario comentar que los resultados académicos que se esperan, comparados con el año anterior, sean óptimos. El uso de las nuevas tecnologías, hacen que los discentes estén más motivados a la hora de aprender, ya que se convierten en los protagonistas y, sin darse cuenta, a través del juego, el aprendizaje es mucho más efectivo.

\section{REFERENCIAS}

Abad-Mas, L., Ruiz Andrés, R., Moreno Madrid, F., Herrero, R., y Suay, E. (2013). Intervención psicopedagógica en el trastorno por déficit de atención/hiperactividad. Revista de Neurología, 57(1), 193-203. https://doi.org/10.33588/rn.57s01.2013290

Accesibilidad Rehasoft. (2012). MeMotiva. https://www.rehasoft.com/tdah/memotiva/ Accesibilidad Rehasoft. (2012). DiTres. https://www.rehasoft.com/dislexia/ditres/

Ariza, M. C. C. (2010). Déficit de atención con hiperactividad (TDAH): Concepto, Características e Intervención Educativa. Revista digital de Innovación y experiencias educativas, 28, 1-8.

https://archivos.csif.es/archivos/andalucia/ensenanza/revistas/csicsif/revista/pdf/ Numero_28/MARIA_CRISTINA_CORTES_ARIZA_01.pdf

Casas, A. M. y Ferrer, M.S. (2010). Tratamientos Psicosociales Eficaces para el Trastorno por Déficit de Atención con Hiperactividad. Información psicológica, (100), 100-114. Dialnet. https://dialnet.unirioja.es/servlet/articulo? codigo $=3642841$

Chin, C. H., Chien T. W. \& Yan Y.H. (2021). Predicting the number of article citations in the field of attention-deficit/hyperactivity disorder (ADHD) with the 100 topcited articles since 2014: a bibliometric analysis. Annals of General Psychiatry, 20(1). DOI: 10.1186/s12991-021-00329-3

Domínguez, M. D. C. A., Figares, C. F., Perales, F. J. G., Ciruela, A. M. G., Chanclón, C. M. O., Díaz, I. P., y Roldán, S. R. (2008). Atención al alumnado con necesidades específicas de apoyo educativo derivadas de trastornos graves de la 
conducta. Manual de la Consejería de Educación de la Junta de Andalucía. http://190.57.147.202:90/xmlui/bitstream/handle/123456789/478/4-trastornosgraves-de-conducta.pdf? sequence $=1$

Espinosa, A. L. (2006). El tratamiento del niño y adolescente con TDAH en Atención Primaria desde el punto de vista de la evidencia. Revista Pediatría de Atención Primaria, (8), 69-114. http://archivos.pap.es/files/1116-594-pdf/619.pdf.

Fernandes, S. M., Piñon Blanco, A. y Vázquez-Justo, E. (2017). Concepto, evolución y etiología del TDAH. http://hdl.handle.net/11328/2091

Galve Manzano, J.L (2010). Intervención Psicoeducativa en el aula con TDAH. Revista de Psicología Educativa, 15(2), 87-106. https://doi.org/10.5093/ed2009v15n2a2

Gómez, T. G., Barranco, N. M., y Mateo, M. A. N. (2009). Trastorno por Déficit de Atención con o sin Hiperactividad: abordaje de Enfermería en el ámbito familiar y escolar. En J. J. Gázquez, M. M. Molero, M. C. Pérez-Fuentes, M. M. Simón, A. B. Barragán y A. Martos, Libro perspectivas y Análisis de la Salud (pp. 6569). ASUNIVEP.

https://formacionasunivep.com/Vcice/files/libros/LIBRO_PERSPECTIVAS.pdf.

González, T. M. (2018). III Congreso Internacional virtual sobre la Educación en el Siglo XXI: TIC y TDAH. 631-638.

https://www.eumed.net/actas/18/educacion/54-tic-tdah.pdf.

González Pérez, T. (2009). Itinerario de la Educación Especial en el sistema educativo.

El largo camino hacia una educación inclusiva: la educación especial y social del siglo XIX a nuestros días: XV Coloquio de Historia de la Educación., 1, 249260. http://hdl.handle.net/11162/45429

Hidalgo Vicario, M.I. (2014). Pediatría Integral: Órgano de expresión de la Sociedad Española de Pediatría Extrahospitalaria y Atención Primaria., 18, 595-597. https://www.pediatriaintegral.es/wpcontent/uploads/2015/01/Pediatr\%C3\%ADaIntegral-XVIII-9.pdf.

Instrucciones de 8 de marzo de 2017, de la Dirección General de Participación y Equidad, por las que se actualiza el protocolo de detección, identificación del alumnado con necesidades específicas de apoyo educativo y organización de la respuesta educativa.

Jiménez Sánchez, E. (2001). El significado oculto del término «necesidades educativas especiales». Revista Interuniversitaria de Formación del Profesorado, (42) ,169-176. ISSN: 0213-8646. https://www.redalyc.org/articulo.oa?id=274/27404212

Latorre-Cosculluela, C., Liesa-Orús, M., y Vázquez-Toledo, S. (2018). Escuelas inclusivas: aprendizaje cooperativo y TAC con alumnado con TDAH. Magis. Revista Internacional de Investigación en Educación, 10(21), 137-152. https://doi.org/10.11144/javeriana.m10-21.eatt

Ley Orgánica 3/2020, de 29 de diciembre, por la que se modifica la Ley Orgánica 2/2006, de 3 de mayo, (BOE del 4 de mayo), de educación. (LOE). https://www.boe.es/eli/es/lo/2020/12/29/3 
Millán, M. J. (2012). Propuesta de metodología docente para alumnos con TDAH. Universidad Internacional de La Rioja. https://reunir.unir.net/handle/123456789/625

Morales, P. T. y Ramos, D. E. G. (2014). Procesos cognoscitivos implicados en la comprensión lectora en tercer grado de educación primaria. Psicogente 17(32), 452-459.https://doi.org/10.17081/psico.17.32.469

Nejati, V. (2021). Program for attention rehabilitation and strengthening (PARS) improves executive functions in children with attention deficit- hyperactivity disorder (ADHD). Research in developmental disabilities, (113), 103937. DOI: 10.1016/j.ridd.2021.103937

Orden de 15 de enero de 2021, (BOJA Extraordinario $n^{\circ}$ 7, 18-01-2021) por la que se desarrolla el currículo correspondiente a la etapa de Educación Primaria en la Comunidad Autónoma de Andalucía, se regulan determinados aspectos de la atención a la diversidad, se establece la ordenación de la evaluación del proceso de aprendizaje del alumnado y se determina el proceso de tránsito entre distintas etapas educativas. https://www.juntadeandalucia.es/boja/2021/507/1

Orden de 17 de marzo de 2015, (BOJA Extraordinario $n^{\circ}$ 60, 27-03-2015) por la que se desarrolla el currículo correspondiente a la Educación Primaria en Andalucía. https://www.juntadeandalucia.es/boja/2015/60/1

Peña Acuña, B. (2020). Creatividad verbal. Barcelona: Octaedro

Peña-Acuña, B. (2019). Innovación aplicada a la Didáctica de la Lengua y la Literatura. Madrid: ACCI

Quiroga, P. (2010) La evolución de la atención a la diversidad del alumnado de educación primaria a lo largo de la historia. Revista Digital Profesionales de la enseñanza, (8), 1-15. https://www.feandalucia.ccoo.es/andalucia/docu/p5sd7241.pdf.

Real Academia Española. (2020). Diccionario de la lengua española (edición de tricentenario). https://www.rae.es/

Sevilla, M. D. G y Garrido J.V.G. (2004). Atención psicopedagógica y familiar en el Trastorno por Déficit de Atención con o sin Hiperactividad. AEPap. Curso de Actualización Pediatría 2004. Exlibris Ediciones, pp. 153-161. https://www.aepap.org/sites/default/files/psicopedagogica.pdf

Young, S., Fitzgerald, M. y Postma, M.J. (2013). TDAH: Hacer visible lo invisible. Libro Blanco sobre el trastorno por déficit de atención con hiperactividad (TDAH): propuestas políticas para abordar el impacto social, el coste y los resultados a largo plazo en apoyo a los afectados. Shire, AG; European Brain Council (EBC); Global Alliance of Mental Illness Avocacy Networks (GAMIAN-Europe). https://consaludmental.org/centro-documentacion/tdahhacer-visible-lo-invisible/ 
Desarrollo de la comprensión lectora en niños con tdah a través de las tic

Know and Share Psychology, 2(3), 61-81 